Journal of Patient-Centered

$1-30-2015$

\title{
Breast Cancer Screening: Early Detection Is Not Enough
}

Judy A. Tjoe

Follow this and additional works at: https://aah.org/jpcrr

Part of the Diagnosis Commons, Medical Genetics Commons, Neoplasms Commons, Oncology Commons, and the Surgery Commons

\section{Recommended Citation}

Tjoe JA. Breast cancer screening: early detection is not enough. J Patient Cent Res Rev. 2015;2:6-8. doi: 10.17294/2330-0698.1044

Published quarterly by Midwest-based health system Advocate Aurora Health and indexed in PubMed Central, the Journal of Patient-Centered Research and Reviews (JPCRR) is an open access, peer-reviewed medical journal focused on disseminating scholarly works devoted to improving patient-centered care practices, health outcomes, and the patient experience. 


\title{
Breast Cancer Screening: Early Detection Is Not Enough
}

\author{
Judy A. Tjoe, MD | Editorial \\ Surgical Breast Oncology, Aurora Health Care, Milwaukee, WI
}

I've never known a woman who looks forward to getting her annual mammogram.

Nonetheless, uncomfortable and anxiety-provoking as it can be, breast cancer screening is effective. While lead time, length and healthy volunteer bias cannot be ignored, ${ }^{1}$ numerous randomized controlled trials and meta-analyses have consistently demonstrated a reduction of $25-35 \%$ in breast cancer mortality associated with routine screening mammography among women age 50-74 years and a reduction of $10-18 \%$ among women age $40-49$ years. ${ }^{2-7}$ A recently published Canadian study following almost 2.8 million women ( $85 \%$ of the country's female population) reported $40 \%$ less breast cancer-related mortality in patients who participated in screening programs versus those who did not (standardized mortality ratio $=0.60$, $95 \%$ confidence interval $0.52-0.67)$. Interestingly, the age at which a woman started screening did not greatly affect the magnitude of this mortality reduction. ${ }^{8}$

Generally, screening is performed with the intent of detecting cancer early and thereby increasing a person's chance of survival from the disease. Cancer screening tests are selected based on their abilities to test asymptomatic populations for disease on a large scale at minimal cost. The test must have a high detection rate of early-stage cancer in order to enable intervention that can lessen future suffering or mortality associated with the disease. In this issue of Journal of Patient-Centered Research and Reviews, two modes of breast cancer screening - radiographic imaging and physical examination - are eloquently reviewed and summarized for today's practice. Dr. Jennifer Lo astutely acknowledges that currently there is insufficient evidence to state clinical breast

Correspondence: Judy A. Tjoe, MD,

945 N. 12th Street, Suite \#2110, Milwaukee, WI, 53233,

T: 414-219-6809, F: 414-219-5815 exam is associated with any survival benefit; however, it may serve, on an individualized basis, as an adjunct to detect heretofore mammographically occult interval cancers, ${ }^{9}$ which are more prevalent in women age 40-49 because of decreased mammographic sensitivity attributable to greater breast density in $68 \%$ of cases. ${ }^{10}$ Dr. Summer Jatala and colleagues propose timing and screening modalities specifically for women with personal or family risk factors. ${ }^{11}$ Breast cancer screening undergoes continuous and intense scrutiny and revision, and recommendations based on a summary of current literature are appreciated by the busy primary care provider faced with constantly evolving data.

Of course, screening programs are only effective for those women who choose to participate. It is important to note that the patient must assume some responsibility for her health and make the effort to attend the clinical breast exam and/or screening mammography appointment. This may sound simple, but, in fact, 33\% of women age $\geq 40$ years who are eligible for screening mammography do not participate, with the percentage rising to $36 \%$ for Hispanic women. In $2010,70 \%$ of patients with no health insurance for more than 12 months did not undergo mammography ${ }^{12}$ in spite of innumerable free screening programs offered nationwide.

Unfortunately, the current state of breast cancer screening, whether by clinical breast exam or mammography, is fraught with drawbacks and limitations.

Early detection comes at a price, both in time and money. That premium is paid by the 1,339 women age 50-59 invited for screening before one breast cancer death is prevented, a number that rises to 1,904 when looking at women who start screening in their $40 \mathrm{~s} .{ }^{13}$ The expense is also shouldered by society as a whole, which must find a way to pay for the approximately 50 million screening mammography exams per 
year, covering $70 \%$ of women in the United States at an annual cost of $\$ 7.8$ billion. The simulated cost of annually screening $85 \%$ of women is reported to be $\$ 10.1$ billion, for which the largest driver of cost is not the cost of mammography imaging, but rather the frequency of screening and the percentage of women screened. ${ }^{14}$ These simulation models do not even consider the growing effect of newer and more expensive screening and diagnostic technologies infiltrating common practice (e.g. magnetic resonance imaging, tomosynthesis and molecular imaging), which, to date, have not been accompanied by data demonstrating survival benefit. Furthermore, if the personal time expended by women being screened is valuable, then more than $\$ 1.5$ billion can be added to annual screening costs by applying the median U.S. hourly wage to an estimated 2 hours allocated for traveling, waiting and receiving screening-related examinations. ${ }^{15}$

Costs aside, screening also can lead to unintended consequences such as false sense of security, misdiagnosis and overdiagnosis. It is not uncommon for a woman discovering she has breast cancer to feel betrayed by years of normal mammograms. Annual mammograms and clinical breast exams do not prevent cancer; they simply detect disease after it has developed. There is anxiety associated with each indeterminate finding that requires additional diagnostic imaging and biopsy to resolve. Approximately 1.6 million breast biopsies are performed every year in the United States, ${ }^{16} 84 \%$ of which identify only a benign finding, i.e. a false positive. ${ }^{17}$ The apprehension felt after a false positive is discovered often extends beyond work-up of the abnormality, well into future years of screening mammography, even though the suspicious finding was found to be benign. The possibility of a false negative also exists, such as with invasive lobular carcinoma presenting as a vague asymmetric density or architectural distortion, a histological type notoriously difficult to detect by screening mammography at early stages. ${ }^{18}$

Perhaps the greatest tragedy of all is that once a breast cancer is diagnosed, we have not yet discovered how to avoid overtreatment by definitively differentiating between malignancies that are programmed to metastasize to vital organs and those "cancers" that have little to no potential to metastasize. Of the
261,000 breast cancers diagnosed in 2010, 54,000 were ductal carcinoma in situ (DCIS), ${ }^{17}$ a noninvasive and thus non-life-threatening disease thought to be a precursor of invasive carcinoma. But we do not know if all DCIS are obligate precursors to invasive disease, which ones are predestined to become an infiltrating malignancy and within what time frame, or whether the DCIS will eventually lead to life-threatening distant metastases. Evidence suggests that death after DCIS is quite rare. After 10-year follow-up of 2,123 patients diagnosed with pure DCIS and treated, Roses and colleagues identified the rate of developing distant breast cancer metastases to be only $0.14 \% .{ }^{19}$

As necessary as regular screening is to detect earlystage breast cancer, clearly there is a critical need to improve these tests.

What is missing from current screening outcomes is the ability to differentiate invasive breast cancers capable of distant metastasis that impact longevity from those breast cancers that will lay dormant for 10 , 20 or even $30+$ years. In an autopsy series of women not known to have had breast cancer during life, the median prevalence of invasive breast cancer was $1.3 \%$ and median prevalence of DCIS was $8.9 \%{ }^{20}$ Even more powerful would be the ability to predict the women originally diagnosed with high-risk markers such as atypia or carcinoma in situ who will not go on to develop an invasive malignancy. If this group could be identified, the rising and concerning trend of prophylactic mastectomies could be avoided. There is much research interest in this particular field, and a few promising predictive and prognostic genomic profiling tests have been developed over the past decade.

In this era of tissue and serum biorepositories, electronic medical records and emerging genetically targeted cancer therapies, we may soon have the capability to analyze the biological samples of women with early noninvasive disease who subsequently develop invasive cancer, identify distinguishing biomolecular signatures from those samples and then develop targeted therapies that abort the process of carcinogenesis. Until then, our best hope for reducing breast cancer-related suffering and mortality is early detection through screening and continued research supported by clinical trials. 


\section{REFERENCES}

1. National Cancer Institute at the National Institutes of Health. Breast cancer screening (PDQ $\left.{ }^{\circledR}\right)$. http://www.cancer. gov/cancertopics/pdq/screening/breast/healthprofessional. Accessed Dec. 31, 2014.

2. Tabar L, Fagerberg G, Duffy SW, Day NE. The Swedish two county trial of mammographic screening for breast cancer: recent results and calculation of benefit. J Epidemiol Community Health. 1989;43:107-14.

3. Tabár L, Chen HH, Fagerberg G, Duffy SW, Smith TC. Recent results from the Swedish Two-County Trial: the effects of age, histologic type, and mode of detection on the efficacy of breast cancer screening. J Natl Cancer Inst Monogr. 1997;(22):43-7.

4. Shapiro S. Periodic screening for breast cancer: the HIP Randomized Controlled Trial. Health Insurance Plan. J Natl Cancer Inst Monogr. 1997;(22):27-30.

5. Miller AB, Baines CJ, To T, Wall C. Canadian National Breast Screening Study: 1. Breast cancer detection and death rates among women aged 40 to 49 years. CMAJ. 1992;147: 1459-76.

6. Alexander FE. The Edinburgh Randomized Trial of Breast Cancer Screening. J Natl Cancer Inst Monogr. 1997;(22):31-5.

7. Kerlikowske K, Grady D, Rubin SM, Sandrock C, Ernster VL. Efficacy of screening mammography. A meta-analysis. JAMA. 1995;273:149-54.

8. Coldman A, Phillips N, Wilson C, et al. Pan-Canadian study of mammography screening and mortality from breast cancer. J Natl Cancer Inst. 2014;106:dju261.

9. Lo J. The clinical breast examination: a useful screening tool? J Patient-Centered Res Rev. 2015;2:34-7.

10. Buist DS, Porter PL, Lehman C, Taplin SH, White E. Factors contributing to mammography failure in women aged 40-49 years. J Natl Cancer Inst. 2004;96:1432-40.
11. Jatala S, Fitzgerald S, Tietze P, Ramakrishnan K, McCarthy LH, Wickersham E. What are the recommended timing and screening modalities for women at higher risk of developing breast cancer? A Clin-IQ. J Patient-Centered Res Rev. 2015;2:38-42.

12. National Center for Health Statistics. Health, United States, 2012: with special feature on emergency care. Hyattsville, MD: U.S. Department of Health and Human Services, 2013.

13. U.S. Preventive Services Task Force. Screening for breast cancer: U.S. Preventive Services Task Force recommendation statement. Ann Intern Med. 2009;151:716-26, W-236.

14. O’Donoghue C, Eklund M, Ozanne EM, Esserman LJ. Aggregate cost of mammography screening in the United States: comparison of current practice and advocated guidelines. Ann Intern Med. 2014;160:145.

15. Elmore JG, Gross CP. The cost of breast cancer screening in the United States: a picture is worth ... a billion dollars? Ann Intern Med. 2014;160:203.

16. Silverstein M. Where's the outrage? J Am Coll Surg. 2009;208:78-9.

17. American Cancer Society. Cancer Facts \& Figures 2010. Atlanta, GA: American Cancer Society, 2010.

18. Evans WP, Warren Burhenne LJ, Laurie L, O'Shaughnessy KF, Castellino RA. Invasive lobular carcinoma of the breast: mammographic characteristics and computer-aided detection. Radiology. 2002;225:182-9.

19. Roses RE, Arun BK, Lari SA, et al. Ductal carcinoma-in-situ of the breast with subsequent distant metastasis and death. Ann Surg Oncol. 2011;18:2873-8.

20. Welch HG, Black WC. Using autopsy series to estimate the disease "reservoir" for ductal carcinoma in situ of the breast: how much more breast cancer can we find? Ann Intern Med. 1997;127:1023-8.

(C) 2015 Aurora Health Care, Inc. 